findings and marked deficits compared to the tic disorder and control groups. In tests of attention, the ADHD group made more errors of commission than the tic disorder with ADHD group. ADHD symptoms found in children with tic disorder may be a true comorbid condition and not secondary to tic symptoms. (Shin M-S, Chung S-J, Hong K-E M. Comparative study of the behavioral and neuropsychological characteristics of tic disorder with or without attentiondeficit hyperactivity disorder (ADHD). I Child Neurol Oct 2001;16:719-726). (Respond: Dr Kang-E Michael Hong, Department of Child Psychiatry, Seoul National University College of Medicine, 28 Youngon-Dong, Chongno-Gu, Seoul 110-744, Korea).

COMMENT. Tic disorder comorbid with ADHD carries an increased risk of cognitive deficits and behavioral disturbance similar to that found with ADHD alone, whereas tic disorder alone is not a risk factor. This report confirms previous findings in a study using transcranial magnetic stimulation to demonstrate additive deficits in inhibitory cortical motor mechanisms in children with ADHD comorbid with tic disorder (Moll GH et al. 2001; see Ped Neur Briefs March 2001;15:22-23).

The prevalence of ADHD in patients with tic disorder has been estimated at more than 50\%. Although the use of stimulants for ADHD associated with tics is controversial, the authors favored early intervention to correct attention and behavioral problems. An exacerbation of tics would probably mandate immediate stimulant withdrawal. For studies of treatments of ADHD and Tics, see Progress in Pediatric Neurology III, PNB Publ, 1997;pp318-321.

\title{
TICS AND SCHOOL DYSFUNCTION
}

The prevalence of tics in special education (SpEd) students and in a matched control sample of students in regular classroom programs (RegEd) was determined in a large-scale, community-based epidemiological study at the University of Rochester School of Medicine, NY. A total of 1596 students (ages 8.517.5 yrs) drawn from the Rochester City School district and 9 surrounding Monroe County suburban public school districts were interviewed from November 1994 to March 1998. Three RegEd subjects were randomly selected for every one SpEd subject. The disability classifications of SpEd students included learning disability (79\%), speech impaired (14\%), emotionally disturbed (5\%), and other (2\%). Interviews of $341 \mathrm{SpEd}$ and 1255 RegEd students were conducted by neuropsychological technicians trained to assess the presence and severity of tics, and to distinguish them from other movements and behaviors. Each technician had spent 3 months with a neurologist, expert in movement disorders, observing approximately 75 children with tics prior to the study. Parent interviews were conducted in the school office or by telephone. RegEd and SpEd students were evaluated in the same time periods, and interviewers were blinded to educational placement. Tics were classified as either definite (observed) or probable (based on historical information), and motor or vocal. The proportion of tics in the SpEd and RegEd groups was $27 \%$ and $19.7 \%$, respectively $(\mathrm{p}=.008)$. The weighted prevalence estimates for tics were $23.4 \%$ for SpEd and $18.5 \%$ for RegEd students. Including only definite tics, the SpEd group still had a higher proportion of tics $(\mathrm{p}=.09)$. A higher percentage of students in SpEd $(7 \%)$ met diagnostic criteria for Tourette syndrome than those in RegEd (3.8\%;p=.01). Thirty percent of students in the SpEd group were receiving stimulant medication compared to $7.5 \%$ of RegEd students. Tics are a common disorder in school children and are strongly azssociated with school dysfunction and placement in special education. (Kurlan R, McDermott MP, Deeley C et al. Prevalence of tics in school children and association with placement in special education. Neurology October 
(2 of 2) 2001;57:1383-1388). (Reprints: Dr R Kurlan, Department of Neurology, University of Rochester School of Medicine and Dentistry, 601 Elmwood Ave, Box 673, Rochester, NY 14642).

COMMENT. This represents a further publication in a long series of studies of tic disorders and Tourette syndrome conducted at the University of Rochester and involving school children in Monroe County. The observed prevalence of tics among children attending regular classes in the present study (18.5\%) is higher than that previously quoted in the literature (4 to 16\%), but the prevalence (27\%) among children in special education is similar (26\%) to a study cited by Robertson MM (Brain 2000;123:425-462). Comparing a group of 35 children in special education with 35 in regular classes, the incidence of tics was $26 \%$ and $6 \%$, respectively. Although the authors of the Rochester study state that only a small number of subjects took medication on the day of the interview, it is noteworthy that $30 \%$ of SpEd students were under treatment with stimulant medication and presumably were diagnosed with ADHD. Despite recent studies that minimize an association (Law SF, Schachar RJ. LAm Acad Child Adolesc Psvchiatry 1999;38:944951; Ped Neur Briefs Aug 1999;13:57-58), our experience and earlier studies have shown that stimulant therapy for ADHD may precipitate tics in susceptible children, and the effect is dose-related (Borcherding BG et al. Psychiatry Res 1990;33:83-94; Tanner CM, Goldman SM. Neurol Clin 1997;15:395-402). Furthermore, tics and Tourette syndrome received no or only passing mention in neurological literature and textbooks until the use of stimulants became popular in the 1960s. (Millichap JG. Tics and Tourette syndrome. In Attention Deficit Hyperactivity and Learning Disabilities. PNB Publishers, 2001). It is prudent to monitor for tics during treatment of ADHD with stimulants.

\section{HYPOTHYROIDISM, MOTOR CLUMSINESS, AND ADHD}

The behavioral characteristics of 63 children with early-treated congenital hypothyroidism $(\mathrm{CH})$ were evaluated by parent and teacher ratings and compared to 34 healthy controls (ages 7.5-9.5 yrs) at the University of Jyvaskyla, Finland. Children with $\mathrm{CH}$, especially those with thyroid agenesis, were more introverted, insecure, and isolated, and showed more motor clumsiness, rather than social negativity and inattention. Children with thyroid agenesis were clumsier than those with thyroid dysgenesis. It is suggested that the motor problems contribute to the introverted behavior. The more severe the thyroid deficiency, the greater probability for behavior problems. The lack of effect on attention challenges claims of an association between $\mathrm{ADHD}$ and thyroid dysfunction. (Kooistra L, Stemerdink N, van der Meere J, et al. Behavioral correlates of early-treated congenital hypothyroidism. Acta Paediatr Oct 2001;90:1141-1146). (Respond: Dr Libbe Kooistra, Research Institute for Olympic Sports, University of Jyvaskyla, University Campus, Rautpohjankatu 6, FIN-40700 Jyvaskyla, Finland).

COMMENT. Early-treated congenital hypothyroidism is associated with introverted behavior and motor clumsiness, and not inattention, impulsivity, and hyperactivity, the core symptoms of ADHD.

\section{SEIZURE DISORDERS}

\section{VIDEO-EEG IN INFANTILE SPASMS}

Early electroclinical manifestations and treatment responses were evaluated by video-EEG in 44 infants with infantile spasms. Mean ages at onset and at first video-EEG were 5.3 and 5.9 months, respectively. Etiology was cryptogenic 